Ghasaq A. Dawood $\mathrm{BPhS}$

Ghada A. Taqa

BVMS, MSc, PhD (Prof)

Manar M. Alnema

BDS, MSc, PhD (Asst. Prof)

\section{Histological Effect of Cytarabine on Liver and Buccal Mucosa in Mice}

\author{
Ministry Of Health-Nineveh Health Directorate \\ Department of Dental Basic Science \\ College of Dentistry, University of Mosul \\ Department of Oral and Maxillofacial Surgery \\ College of Dentistry, University of Mosul
}

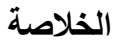

الاهداف: يهدف البحث الى تقييم التأثير النسيجي المرضي لعقار الستر ابين على الكبد ونسيج الخد في الفئران. المواد وطرائق العمل: تم اختيار

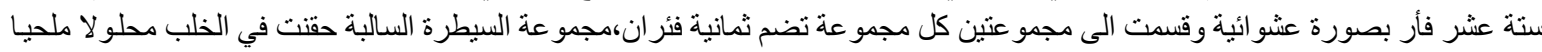

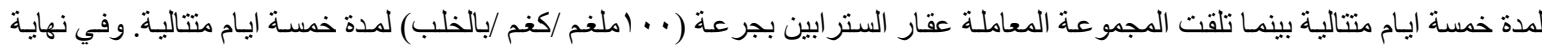

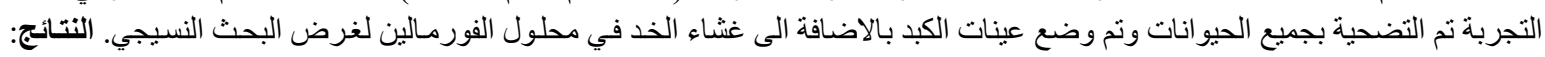

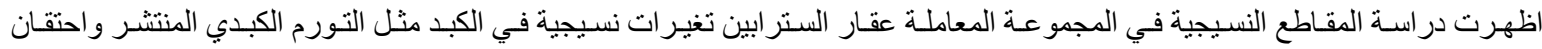

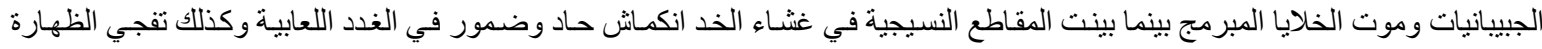

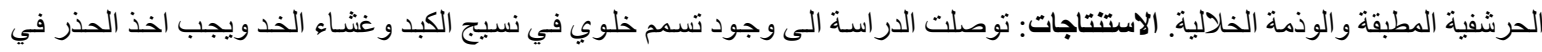

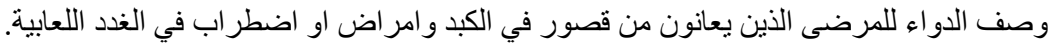

\begin{abstract}
Aims : This study aimed to investigate the histopathological effect of cytarabine drug on liver and buccal mucosa in mice. Materials and Methods: Sixteen male albino mice were randomly assigned to two experimental groups and housed as eight animals /cage as a group.Control Group: was given daily I.P distilled water for 5 days. Cytarabine Group: was given daily Cytarabine at dose $(100 \mathrm{mg} / \mathrm{kg} / \mathrm{I} . \mathrm{P})$ for 5 days. At the end of experiment, all animals were sacrificed and liver in addition to the buccal mucosa were excised and placed in 10\% buffered formalin solution for histological preparation and evaluation. Results: histopathological study of cytarabine treatment group showed multiple changes in liver like defused vacuolar swelling with abnormal hepatic cords patterns, congested sinusoids and multiple foci of apoptotic cells while in buccal mucosa sections revealed a severely shrinkaged and atrophied appearance of mucus-salivary glands, vacuolation of the stratified squamous epithelium and interstitial edema. Conclusions: this study concluded the direct cytotoxicity of cytarabine to liver and buccal mucosa. So caution should be taken when administrating the drug to patient with liver or salivary glands dysfunction.
\end{abstract}

Key words: Cytarabine, Buccal mucosa, Mice, chemotherapy.

Dawood Gh A., Taqa Gh A., Alnema M M. Histological Effect of Cytarabine on Liver and Buccal Mucosa in Mice. Al-Rafidain Dent J. 2020 ;20 (1):36-45.

DOI: 10.33899/rden.2020.164521

Received: 4/2/2020 Sent to Referees: 5/2/2020 Accepted for Publication: 26/4/2020 


\section{INTRODUCTION}

Cancer is considered as a serious worldwide health problem, being the second leading reason of global spontaneous mortalities after cardiovascular diseases. The reason behind developing rapidly may be mainly due to environmental carcinogens and unhealthy lifestyles ${ }^{(1)}$. The mode of treatment depends on the type, site, and grade of cancer, the step of the disease and the overall health of the patient ${ }^{(2)}$.

Chemotherapeutic agents are the compounds that used in cancer treatment and they are varying in structure and mechanism of action. Cytarabine or Cytosine arabinoside (Cytosar $\left.{ }^{\circledR}\right)$ is a pyrimidine nucleoside-based chemotherapeutic agent. Cytarabine is called cytosine arabinose because it combines a cytosine base with an arabinose sugar ${ }^{(3)}$. It is a cell-phase-specific chemotherapeutic drug, primarily act during the $\mathrm{S}$ phase when cells are undergoing DNA synthesis ${ }^{(4)}$. It causes extensive chromosomal destruction through induction of chromatoid aberrations ${ }^{(5)}$. Thus Rapidly dividing cells, which need DNA replication for mitosis, are the mostly affected (3)

This drug, used to treat acute myeloid leukemia (AML), acute lymphocytic leukemia (ALL), chronic myelogenous leukemia (CML), and non-Hodgkin's lymphoma ${ }^{(6)}$. Also used as an antiviral agent against herpes simplex virus and human cytomegalovirus ${ }^{(7)}$.

It is administered through continuous intravenous infusion or injection, intrathecally or subcutaneously then after three phosphorylation steps cytarabine is transformed to cytarabine triphosphate ${ }^{(8)}$. The majority of the drug is metabolized in the kidney, liver and gastrointestinal tract into its inactive metabolite and large amount of the administered dose is eliminated by renal excretion within one day ${ }^{(9)}$. It is Common side effects include vomiting, liver function disturbances, diarrhea, bone marrow suppression, oral mucosal ulceration, rash, and bleeding ${ }^{(10)}$.

Aims of study: This study aims to investigate the side effect of cytarabine drug on liver and buccal mucosa in mice through the histopathological examination.

\section{MATERIALS AND METHODS}

The drugs injection was done at the pharmacology laboratory of Department of dental basic sciences at college of dentistry / university of Mosul / Iraq from 1/9/2019 to 20/1/2020.

\section{Laboratory animals}

Sixteen healthy adult male albino mice weighing (25-30) gm obtained from the Animal House of Experimental Research Unit, College of veterinary medicine, University of Mosul, Iraq. They housed in rodent plastic cage with 
steel wire mesh covers at $(22 \pm 2){ }^{\circ} \mathrm{C}, 12 \mathrm{hr}$ light $/ 12$ hr. dark cycle and received standard laboratory diet and water. Animals permitted to acclimate one week before experiment. This study was done in accordance with the guidelines of the institutional animal research ethics committee / college of dentistry/ University of Mosul.

\section{Experimental Design}

Sixteen male albino mice were randomly assigned to two experimental groups and housed as eight animals per cage, and each group was treated as the following: Group A: served as normal control group and was given daily intraperitonial injection of distilled water at dose $(5 \mathrm{ml} / \mathrm{kg})$ for 5 days. Group B: was given daily intraperitoneal injection of Cytarabine at dose $(100 \mathrm{mg} / \mathrm{kg}){ }^{(11)}$ for five days. At the end of experiment, all animals of each groups were sacrificed and liver in addition to the buccal mucosa were excised and preserved in $10 \%$ buffered formalin for histological investigation.

\section{Tissue preparation for histopathological study}

Liver and buccal mucosa of each mice were prepared for histological study by preserving them in solution of $10 \%$ neutral buffered formalin for 24 hours in order to be fixed, after that the tissues were dehydrated by using a gradual concatenations of ethyl alcohol (70\%-100\%) for a period of (30minutes) for each concentration. Then the samples were cleared in 2 separated xylene changes before Passing them in 2 stages of paraffin wax at 57 degree temperature for impregnation, then embedding with paraffin in blocks for sectioning. Following that the samples were cross sectioned at $5 \mu \mathrm{m}$ thickness, later on it stained by hematoxylin and eosin (HE) stain to examine the histological changes by means of light microscope ${ }^{(12)}$.

\section{RESULTS}

Histopathological alterations of liver sections in mice in control group sections showed normal cellular and structural details including normal hepatic cord cells around central vein and normal portal areas Figure (1) where as in cytarabine treated group there was defused vacuolar swelling with abnormal hepatic cords patterns and more sever at centrio-lobular Zones also there was multiple foci of apoptotic cells, congested sinusoids and minimal inflammatory response were noticed.

Figures $(2,3)$ 


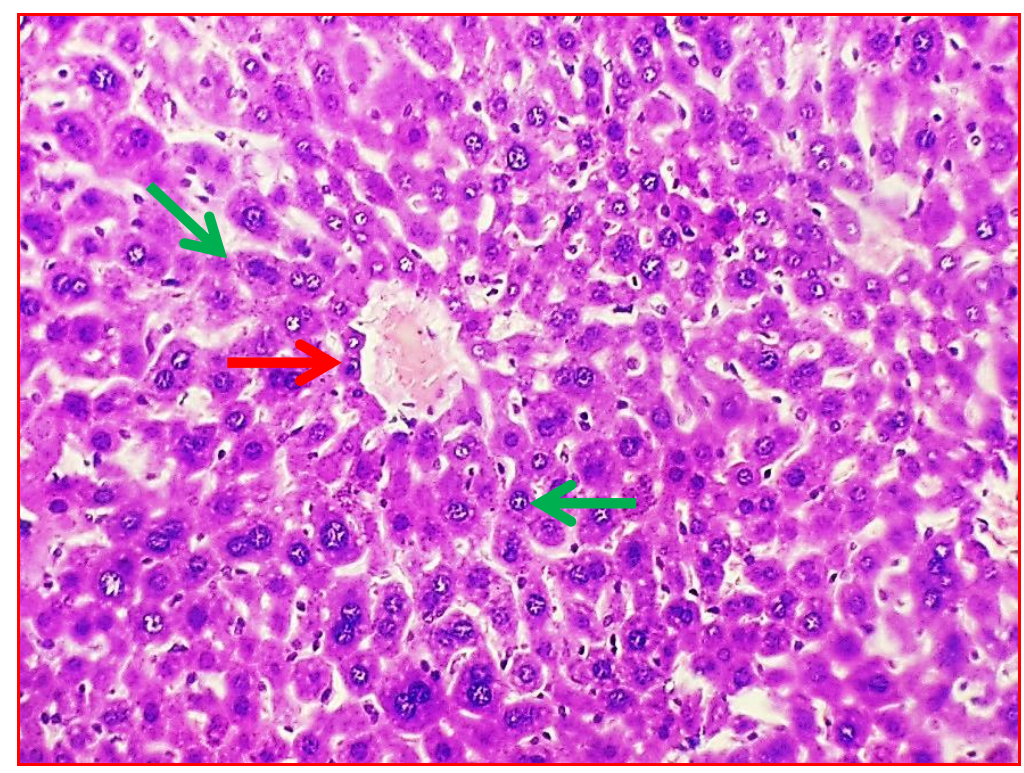

Figure (1): Photomicrograph of mouse liver section from control group showing normal cellular and architectural details of the central vein $(\rightarrow)$ and hepatic cords $(\rightarrow)$. Staining H\&E.

Magnification $200 \mathrm{X}$.

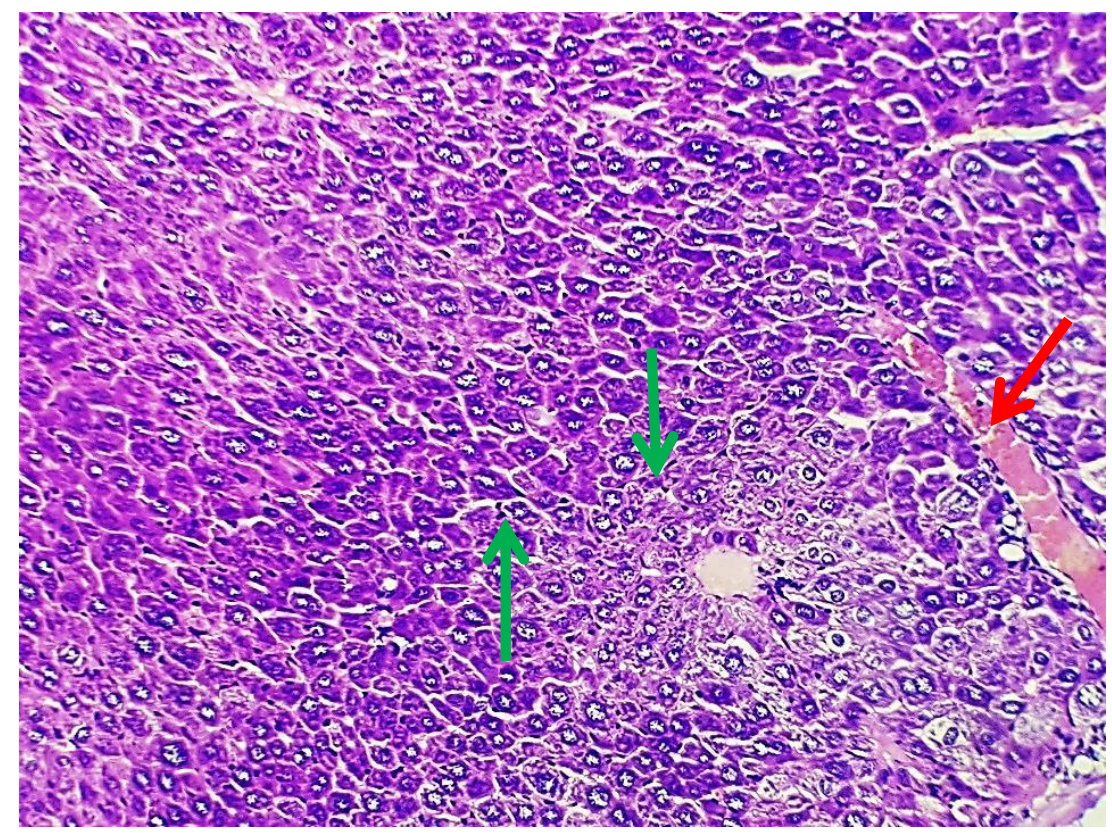

Figure (2) : Photomicrograph of mouse liver section from cytarabine treated group showing moderately congested sinuses $(\rightarrow)$ acute centro-lobular hepatic cell swelling with hepatic cords dysregulation $(\rightarrow)$. Staining H\&E. Magnification 145 X. 


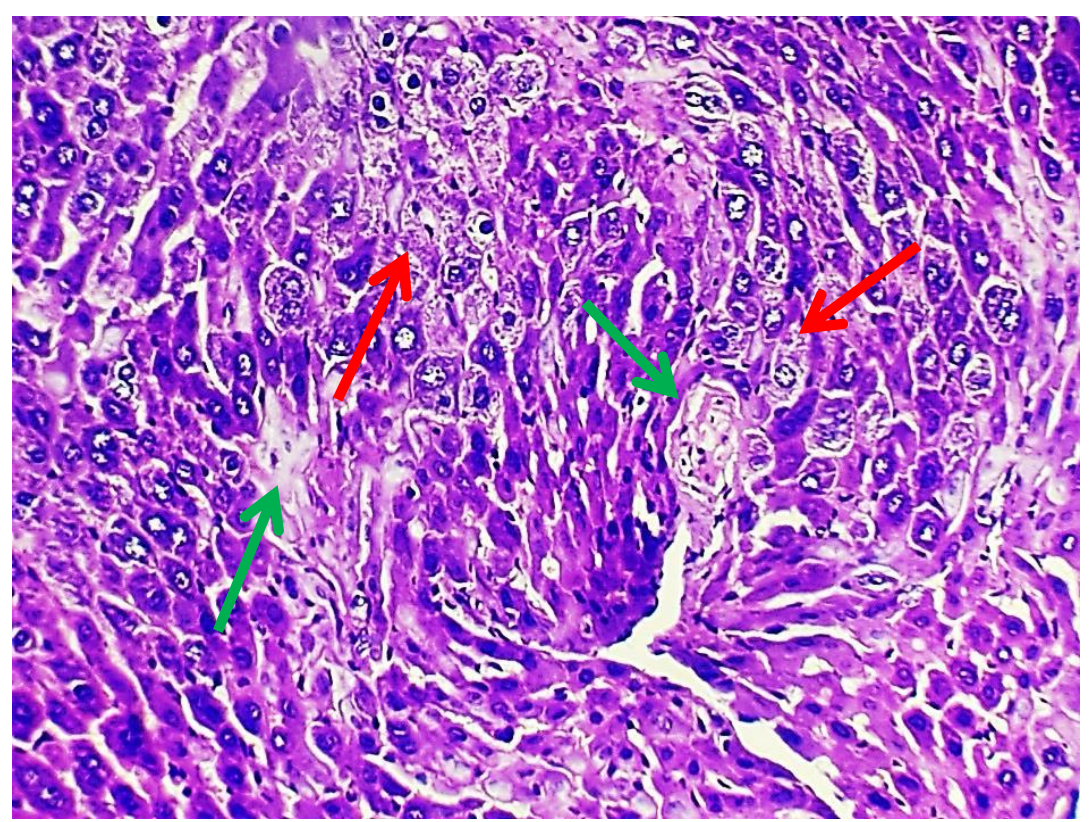

Figure (3): Photomicrograph of mouse liver section from Cytarabine treated group showing acute vacuolar cell swelling $(\rightarrow)$ different stages of Apoptotic necrosis of hepatic cells $(\rightarrow)$. Staining H\&E. Magnification 256 X.

In concern with histopathological lining, normal mucous - salivary glands, modifications in buccal mucosa in control normal ducts opening normal vasculature and group showed normal squamous epithelial under lining tissue. Figures $(4,5)$

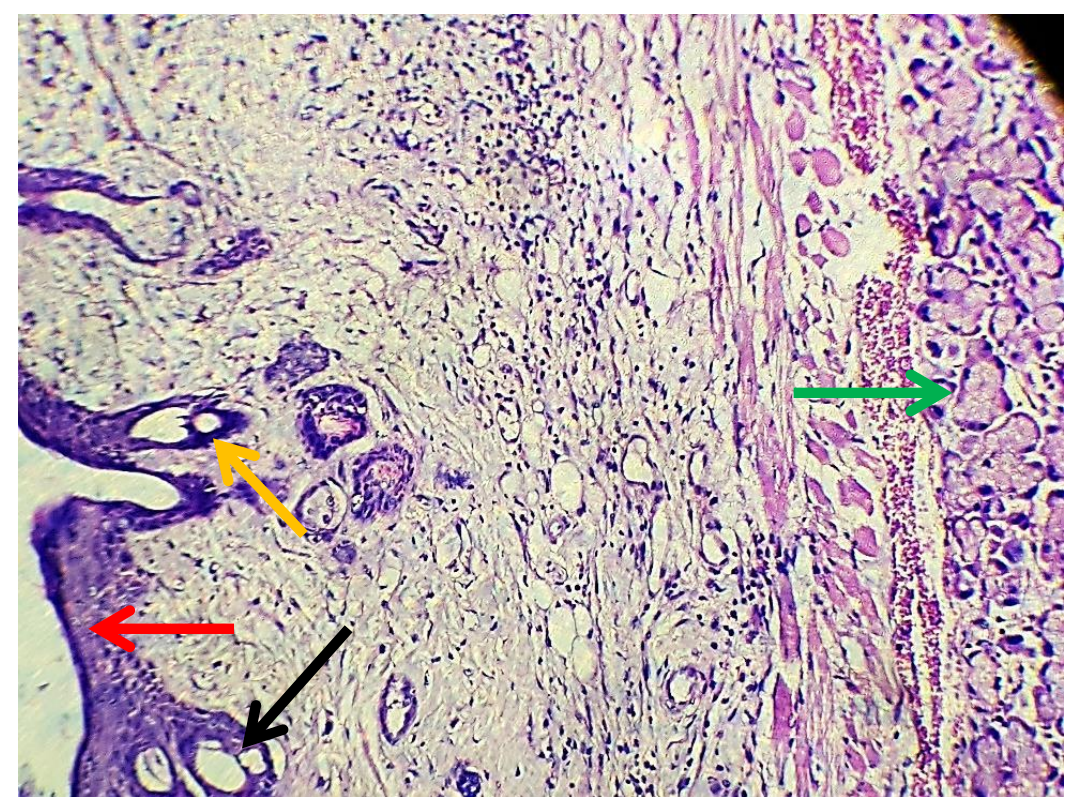

Figure (4): Photomicrograph of mouse buccal mucosa section from control group showing normal epithelium $(\rightarrow)$ normal salivary glands $(\rightarrow)$ normal mucous glands $(\rightarrow)$ and normal ducts $(\rightarrow)$. Staining H\&E. Magnification 115 X. 


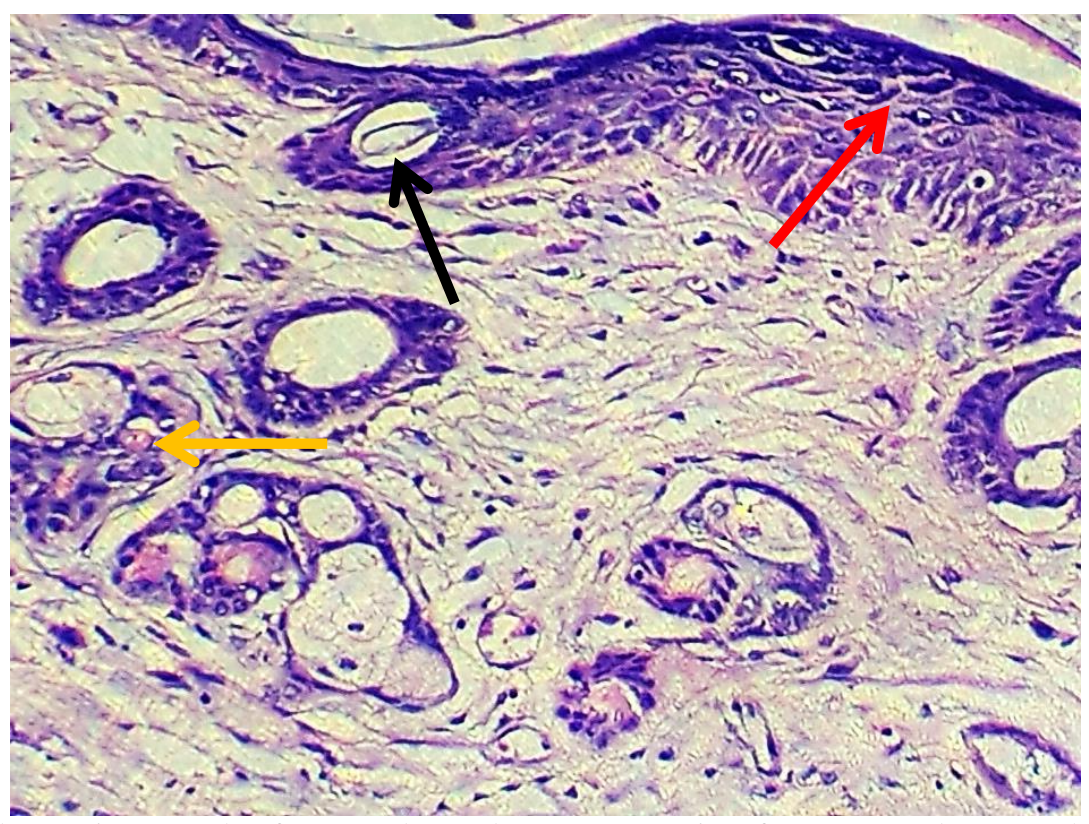

Figure (5): Photomicrograph of mouse buccal mucosa section from control group showing normal epithelium $(\rightarrow)$ normal mucous glands $(\rightarrow)$ and normal lobular ducts $(\rightarrow)$. Staining H\&E. Magnification 256 X.

While in cytarabine treated group revealed glands, reduction of diameter of inter lobular a severe shrinkage and atrophied appearance of and lobular salivary ducts, vacuolation $f$ the mucus-salivary glands, zymogen granules stratified squamous epithelium and interstitial depletion in the cytoplasm of serous cells of the edema. Figures $(6,7)$

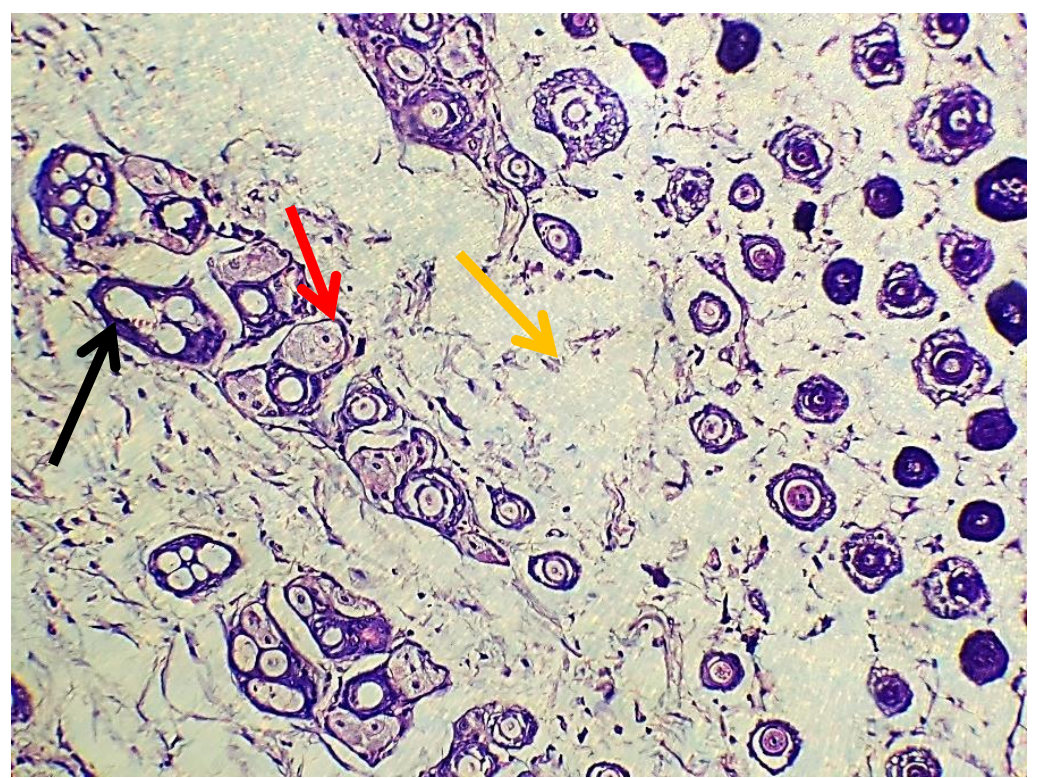

Figure (6): Photomicrograph of mouse buccal mucosa section from Cytarabine treated group showing shrinkage and atrophy of mucous glands $(\rightarrow)$ interstitial sub mucosal edema $(\rightarrow)$ empty lobular ducts $(\rightarrow)$. Staining H\&E. Magnification 115 X. 


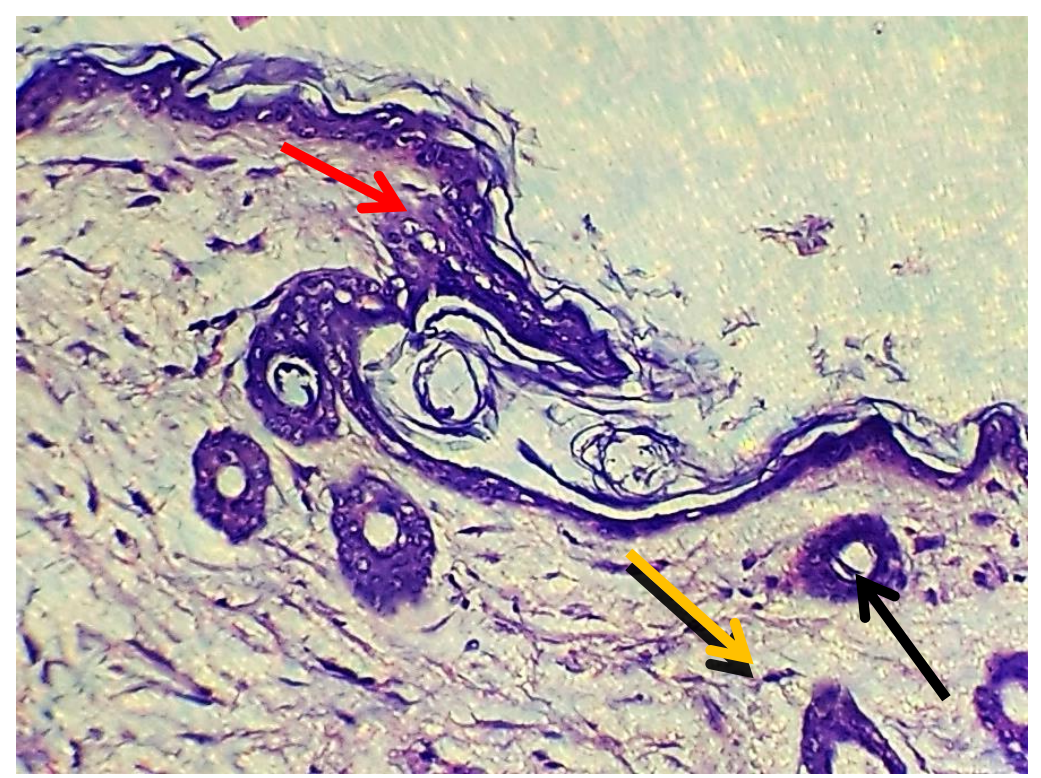

Figure (7): Photomicrograph of mouse buccal mucosa section from Cytarabine treated group showing Vacuolation of the stratified squamous epithelium $(\rightarrow$ ) interstitial sub mucosal edema $(\rightarrow)$ sloughing of lobular ducts lining cells $(\rightarrow)$. Staining H\&E. Magnification 265 X.

\section{DISCUSSIONS}

Histology of liver sections in cytarabine group showed defused vacuolar swelling with abnormal hepatic cords patterns also there was congested sinusoids and multiple foci of apoptotic cells and minimal inflammatory response were noticed. This current result explained by oxidative damage that leads to mitochondrial DNA damage (mtDNA) and those changes related to DNA fragmentation and apoptosis initiation ${ }^{(13)}$.

This result in agreement with previous study of histological changes of cytarabine in tissue sections of liver and shown dissimilar levels of hepatic apoptosis and cell necrosis which can lead to incomplete or disappearance of the nucleus and cell membrane. Apoptotic cells will separately scatter in tissues with concentration of the nuclear chromatin and spallation of the nucleus ${ }^{(14)}$.

As well as similar to result obtained by other study of the histopathological effects of cisplatin, doxorubicin and 5-flurouracil on the liver of rats and mentioned that there is ultrastructural abnormalities in the liver including marked disruption of hepatic cords and dilated blood sinusoids, inflammatory infiltration, periportal fibrosis, hyperplasia and many hepatocytes showed karyomegaly and pyknotic nuclei representing apoptosis ${ }^{(15)}$ .Regarding histopathological result of current study in buccal mucosa showed severe shrinkage and atrophied appearance of mucus- 
salivary glands, zymogen granules depletion in the cytoplasm of serous cells of the glands , reduction of diameter of inter lobular and lobular salivary ducts, vacuolation $f$ the stratified squamous epithelium and interstitial edema. This result may be explained through the fact that Cytarabine is determined as most recorded mucotoxic agents that damage the entire gastrointestinal tract, from oral cavity to anus ${ }^{(16)}$. In general chemotherapy are drugs that having a direct cytotoxic activity, so any normal tissue from the body is possibly vulnerable and can be affected, earlier or later and due to the lack of high selectivity of the antineoplastic drug on tumor tissue that can't distinguish between cancer cells and cells of rapidly dividing normal tissue, such as digestive epithelial tissue as a result it can cause structural or functional changes in the digestive tract ${ }^{(17)}$. Most of chemotherapeutic agent like cytarabine acts through direct DNA damage then cytokines enter the circulation and activate an inflammatory cascade. Both intrinsic and extrinsic apoptotic pathways are up regulated and mucosal integrity is damaged by inflammatory infiltrates and tight junction interruption $^{(18)}$. Additionally, Primary mucosal cell injuries resulting from oxidative stress lead to the genes expression as early response and activation of DNA transcription factor as well as chemotherapy affects salivary glands function leading to temporary or permanent dysfunction that can result in saliva secretion reduction and inadequate composition also chemotherapy affect microflora diversity and load; this imbalance responsible for opportunistic infections or the reactivation of latent viruses ${ }^{(19)}$. This current result in line with previous study of pathophysiology behind xerostomia and reduced function of the salivary glands during and after chemotherapy and mentioned that Antimetabolites chemotherapy (5-fluorouracil, methotrexate and cytarabine) cause nuclear degeneration, Vacuolization, ductal dilatation, inflammation, cyst formation and reduced salivary flow rate (20). Also this result similar to result obtained by other study regarding the effect of methotrexate on parotid gland and mentioned that most of the serous acini had irregular outlines and was widely separated; ductal cells were faintly stained with variable sized vacuoles displacing the nuclei more peripherally and marked hemorrhage between acinar cells and the cytoplasm ${ }^{(21)}$. As well as in consistence with another study regarding the effect of methotrexate on rabbits submandibular salivary gland and reported that there was a glandular degeneration detected by marked vacuolations in acinar and ductal cells and complete replacement of some acinar cells by large vacuoles ${ }^{(22)}$.

\section{CONCLUSIONS}

Although cytarabine is the highly effective in treatment of cancer but it is associated with direct cytotoxicity to organs and tissues such as liver and buccal mucosa so caution should be 
taken when giving the drug to patient with liver disease or failure and salivary glands dysfunction.

\section{Acknowledgment}

The authors are very grateful to the University of Mosul \ College of Dentistry for their provided facilities, which helped improve the quality of this work.

\section{REFERENCES}

1. Bray F, Ferlay J, Soerjomataram I, Siegel R, Torre L, Jemal A. Global cancer statistics 2018: GLOBOCAN estimates of incidence and mortality worldwide for 36 cancers in 185 countries. Ca Cancer J Clin. 2018; 68: 394424.

2. Hayden EC. Cutting off cancer's supply lines. Nature. 2009; 458(7239): 686-687.

3. Konda N, Prashanth, P, Arvind G, and Shah S. Pharmaceutical development and compatibility studies on cytarabine injection. Asian J. Pharm. Clin. Res. 2013; 6(3): 142145 .

4. Megías-Vericat JE, Montesinos P, Herrero MJ, Bosó V, Martínez-Cuadrón D, Poveda JL, et al. Pharmacogenomics and the treatment of acute myeloid leukemia. Pharmacogenomics. 2016;17(11):1245-72

5. Ma J, Li X, Su Y, Zhao J, Luedtke A, Epshteyn V, Ge Y. Mechanisms responsible for the synergistic antileukemic interactions between
ATR inhibition and cytarabine in acute myeloid eukemia cells. Sci. Rep. 2017; 7(1), 41950.

6. Pigneux A, Perreau V, Jourdan E, et al. Adding lomustine to idarubicin and cytarabine for induction chemotherapy in older patients with acute myeloid leukemia: the BGMT 95 trial results. Haematologica.2007; 92 (10): 1327-34.

7. Liu J, Jiang Y, Cui Y, Xu C, Ji X, Luan Y. Cytarabine-AOT catanionic vesicle-loaded biodegradable thermosensitive hydrogel as an efficient cytarabine delivery system. Int $J$ Pharm.2014; 473:560-571

8. Yin B. Trp53 loss during in vitro selection contributes to acquired Ara-C resistance in acute myeloid leukemia. Experimental Hematology.2005; 34: 631-641.

9. Murphy T, Yee K. W. L. Cytarabine and daunorubicin for the treatment of acute myeloid leukemia. Expert Opinion on Pharmacotherapy.2017; 18(16): 1765-1780.

10. Löwenberg B, Pabst T, Vellenga E, van Putten W, Schouten H. C, Graux C, Ossenkoppele G. J. Cytarabine Dose for Acute Myeloid Leukemia. New England Journal of Medicine. 2011; 364(11): 10271036.

11. Cano F, Pannel R, Follows G. A, Rabbitts T. H. Preclinical modeling of cytosine arabinoside response in Mll-Enl translocator mouse leukemias. Molecular Cancer Therapeutics. 2008; 7(3): 730-735. 
12. LUNA, L.G. 1968. Manual of Histologic Staining Method of the Armed Forces Institute of Pathology. 3rd Edn. McGraw Hill Co., USA; Pp. 1-46.

13. Mustafa N, El Awdan A, Hegazy A, Abdel Jaleel A. Prophylactic role of coenzyme Q10 and Cynara scolymus L on doxorubicin-induced toxicity in rats: Biochemical and immunohistochemical study. Indian journal of pharmacology. 2015; 47 (6): 649-656.

14. Liu R, Jiang Y, Hu X, Wu J, Jiang W, Jin G, Luan Y.

A preclinical evaluation of cytarabine prodrug nanofibers assembled from cytarabine-lauric acid conjugate toward solid tumors. International Journal of Pharmaceutics. 2018; 552(1-2):111-118.

15. El-Sayyad I, Ismail F, Shalaby F, Abou-ElMagd R, Gaur R, Fernando A, Raj M, and Ouhtit A. Histopathological effects of cisplatin, doxorubicin and 5-flurouracil (5-FU) on the liver of male albino rats. Int J Biol Sci. 2009; 5(5): 466-473.

16. Sasu A, Onel M, Balta C, Ghib-Para1 C, Miutescu M, Cotoraci C. Mucositis pathology in chemotherapy induced digestive toxicity. Jornal of Medical Aradean. 2016; XIX (1):1220

17. Boussios S, Pentheroudakis G, Katsanos K, Pavlidisa N, Systemic treatment-induced gastrointestinal toxicity: incidence, clinical presentation and management. Ann Gastroenterol. 2012; 25(2): 106-118.
18. Marcussen M, Skrubbeltrang C, Bødker J, Christiansen I, Bøgsted M, Dybkær K, Johnsen E.2017). A systematic review of molecular responses to cancer therapy in normal human mucosa. Oral Surgery, Oral Medicine, Oral Pathology and Oral Radiology.2017; 124(4):355-366. doi:10.1016/j.oooo.2017.08.002

19. Wojciechowicz J, Kostyra M, Kozińska J, Hus M, Tomaszewski T. Oral mucositis in patients with leukaemia following high-dose chemotherapy and autologous haematopoietic stem cells transplantation. Acta Haematologica Polonica. 2014; 45(3): 258-263.

20. Jensen S, Pedersen A, Reibel J, Nauntofte B. Review article (xerostomia and hypofunction of the salivary glands in cancer therapy). Support Care Cancer. 2003; 11: 207-225

21. Abdel-Fatah S, Yousef D, AL-Semeh A. Oxidative Stress Changes Induced by Methotrexate on Parotid Gland Structure of Adult Male Albino Rat: Can Vitamin C Ameliorate These Changes? Med. J. Cairo Univ., 2019; 87(4): 2555-2565.

22. MAHMOUD F, MAHMOUD F, ABD-ALHALEEM M. Royal Jelly ameliorates oxidative stress and tissue injury in submandibular salivary gland of methotrexate treated rabbits: Immunohistochemical study. J. Am. Sci. 2012; 8: 501-8. 